\title{
Making the transition
}

\section{to the SuperCatalog:}

\section{ISU's experience with LUIS II}

\author{
By H. Seott Davis \\ Head, Department of Library Instruction \\ and Orientation \\ Indiana State University, Terre Haute
}

and Patricia L. Ensor

Coordinator, Electronic Information

Services

Indiana State University, Terre Haute

\section{The fall meeting of the Indiana Online Users Group focuses on expanding access to information.}

1 he concept of the SuperCatalog is one that has recently received much attentionthe focus of programs at ALA midwinter and annual conferences in 1990. The recent implementation of the SuperCatalog concept at Indiana State University (ISU) in Terre Haute, Indiana, was the centerpiece of the November 9,1990 , fall program of the Indiana Online Users Group. "Expanding Access to Information" was the theme. Fifty-three of the approximately 100 members of the state organization heard presentations which included a discussion and demonstration of LUIS II, ISU's SuperCatalog.

A SuperCatalog is a computerized library catalog that goes beyond providing access to a local library's holdings. It may include access to (nonOPAC) locally produced databases, commercially produced databases loaded locally, information gateways to distant databases, and interlibrary linkages that allow transactions between different institutions.

ISU brought up the NOTIS system in 1985 . Since that time numerous enhancements have made it easier for users to access information. Among these are the implementation of keyword/ Boolean searching, loading of government document tapes, and online access to serials holdings. ISU's movement toward the SuperCatalog model began last August with the local loading of ERIC and a selection of H.W. Wilson databases.

\section{Pre-implementation decisions}

Once the decision was made to load databases locally, the first question was: which software to use? The two realistic contenders in late 1989 were BRS Search Software and NOTIS Multiple Database Access System (MDAS) software. The BRS software was well established and used for accessing multiple databases by several academic libraries, including Clemson University, a NOTIS site. The BRS software allowed sophisticated search formulations and supported desirable print functions; it also had been used to create local databases and worked with a wide variety of commercial databases. In comparison, NOTIS MDAS software was relatively new, it supported only a small range of databases, and did not initially support creation of local databases. It used the author, title, subject, and simple keyword/Boolean search capabilities of the NOTIS OPAC, which allow only one search statement and screen dumps for printing.

NOTIS MDAS software had a number of advantages for ISU, however. The overriding ones proved to be the retention of the same interface used to search the OPAC and ease of switching 
from one database to another, including transferring a search from one database to another without rekeying the search statement. NOTIS was promising the capability of linking article citations to OPAC serial holdings, a capability that would be more difficult to engineer with software from two different companies. Having both the OPAC and local database software from the same producer was bound to produce desirable working compatibility in the future. NOTIS was also willing to work with ISU toward developing a loader program for ERIC, one of the databases ISU wanted to load.

After deciding on NOTIS software, we turned our attention to the question: What databases do we offer? This decision was based on three factors: user need, affordability, and availability through NOTIS. ERIC on SilverPlatter had proven popular with students during the preceding two years; queuing problems had resulted in two subscriptions to the CD-ROM database. ERIC also met the affordability test and, as noted earlier, NOTIS was willing to develop the necessary loader program.

A combination of Wilson indexes (Social Science Index, Business Periodicals Index, Humanities Index, and General Science Index) was selected for loading as a single database. These particular indexes were chosen because it was felt that they represented a broad range of subjects that would serve both graduate students and undergraduates. The ERIC and Wilson databases fit well with fiscal resources and mainframe computing space available at the time.

\section{Naming the new system}

ISU's OPAC had always been known as LUIS (Library User Information System). ERIC was an established database name and met the four-character limit imposed by MDAS for database labels. Naming the Wilson indexes posed more of a problem, since we were combining four distinct indexes into one electronic database. Finally, WILI was chosen as the name for the database containing the Wilson indexes.

After the databases that would be available through the libraries' new system were named, it became obvious that a new name was needed for the overall system. Library users already associated the name "LUIS" with the libraries' "computer," even though LUIS was technically the name of ISU's online catalog of local holdings. After much discussion, it was decided to rename the overall system LUIS II. This new name preserved users' association of "LUIS" with the libraries' computer system. Using the numeral II implied a "new and improved" LUIS and offered flexibility for upgrading the name to reflect future enhancements. LUIS II would offer users a choice of three databases: LUIS, WILI, and ERIC.

\section{Organizational impact}

Implementation of LUIS II has had a variety of organizational impacts. Even before the new system was implemented, staff training began, and will be ongoing due to a continuous rate of system changes and improvements. The Department of Library Instruction \& Orientation (LI\&O) provides general orientations for library staff on major system changes. Detailed training is done by NOTIS and individual departments.

$\mathrm{LI} \& \mathrm{O}$ also promotes the new service to users, another ongoing concern. LUIS II was publicly introduced with a major promotional campaign which included a new symbol to convey the idea of LUIS II-a strongman holding three spheres, each with individual database names. A special issue of the library newsletter for ISU faculty, staff, and administrators featured LUIS II. LUIS II continues to be covered in all library instruction sessions offered by LI\&O.

Dial access to LUIS II has been a major concern. Access to ERIC is not as much of an issue, since it is a government-sponsored, non-copyrighted database, but access to WILI must be controlled. Database producers understandably do not want campus databases to compete with their own online products. The library has always prided itself, however, on free public access to LUIS through dial-in. Reconciling these two concerns in a way that is not cumbersome to the user has now been done through a dial-access, front-end menu purchased from another NOTIS institution and adapted. ISU Libraries reworded the two screens seen by the user, and they clearly make only LUIS available to non-ISU users, while allowing ISU users to enter their ID numbers and gain access to all three database options.

The impact on interlibrary loan requests is not yet fully known. An increase is definitely expected, since the library does not own all of the materials in WILI or ERIC. Although users now have access to article citations in the library's computer system, this still does not help the procrastinating student to obtain actual materials.

Another major impact has been on computing equipment. These databases occupy a great deal of mainframe space-in the case of ERIC, more than was expected. This affects processing time for all searches, and some complicated ERIC searches simply will not yet nun. This has implications for future investment of funds in systems equipment.

\section{Impact on library instruction}

The impact of LUIS II on library instruction efforts at ISU has been significant. Most obvious is the increase in instructional content for the usual 50-minute, one-shot lecture. Luckily, many faculty 
who regularly request library instruction for their classes are allowing two class sessions for introducing LUIS II and other library concepts. The instruction librarians have begun to shift emphasis from purely mechanical, "how-to-search" procedures to more cognitive concepts: database structure and fields; differences between databases in terms of content, purpose, coverage, and subject authority; and keyword/Boolean searching not specific to a particular database.

The rate of system change brought on by NOTIS' continuing development of the MDAS software poses another challenge. Instructional materials often need revision to reflect some improvement in the system's capabilities. Also, the rate of change makes it difficult for the instruction librarians to stay abreast of all developments and keep end users and library staff aware of the changes. Perhaps the rate of change will lessen in the future as the SuperCatalog moves beyond its early stages of development. In the meantime, the instruction librarians are learning to accept the rate of change as a challenge rather than an annoyance.

Finally, changes specific to end-user searching (even though they are improvements) seem to diminish the year-to-year continuity of instruction efforts. What a student learns this year about searching in LUIS II may not apply after subsequent software releases are installed. Perhaps the time is near for a required course in information management for all students, or at the very least, more rigorous and pervasive course-integrated instruction.

\section{Future developments}

The future of ISU's SuperCatalog, LUIS II, is bright. A significant enhancement slated for the near future is what NOTIS is calling "hook-toholdings." Hook-to-holdings will allow users to determine very quickly the local availability of journal articles retrieved in an ERIC or WILI search. A long-term project currently underway in Indiana is a statewide undertaking known as SULAN, State University Libraries Automation Network. SULAN is a multi-phase cooperative effort which will ultimately allow Indiana's library users to access the collections of participating institutions' libraries and initiate their own interlibrary loan requests.

Making the transition from the single database/ OPAC model to the SuperCatalog is not entirely painless; however, it has been said, "no pain, no gain." The concept of the SuperCatalog represents a new generation of online public access systems. One would be hard pressed to argue that the concept and the reality are not inherently good.

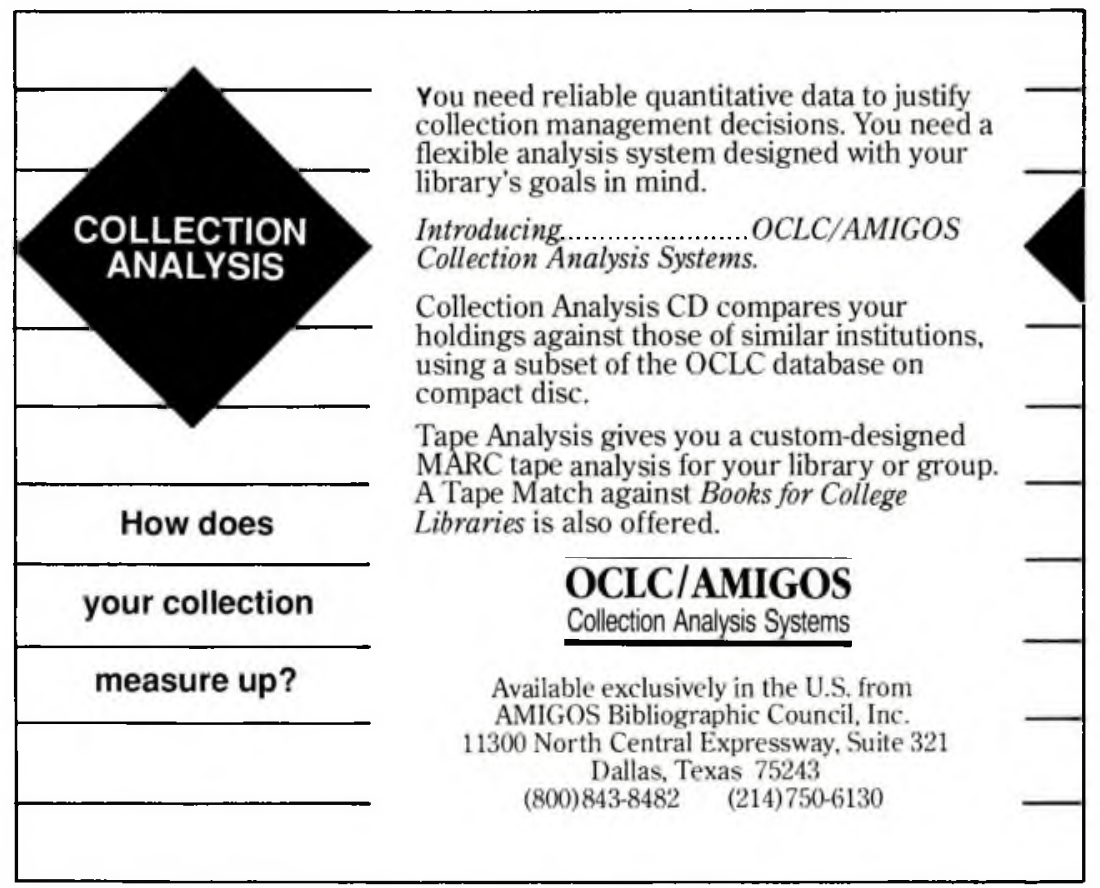

